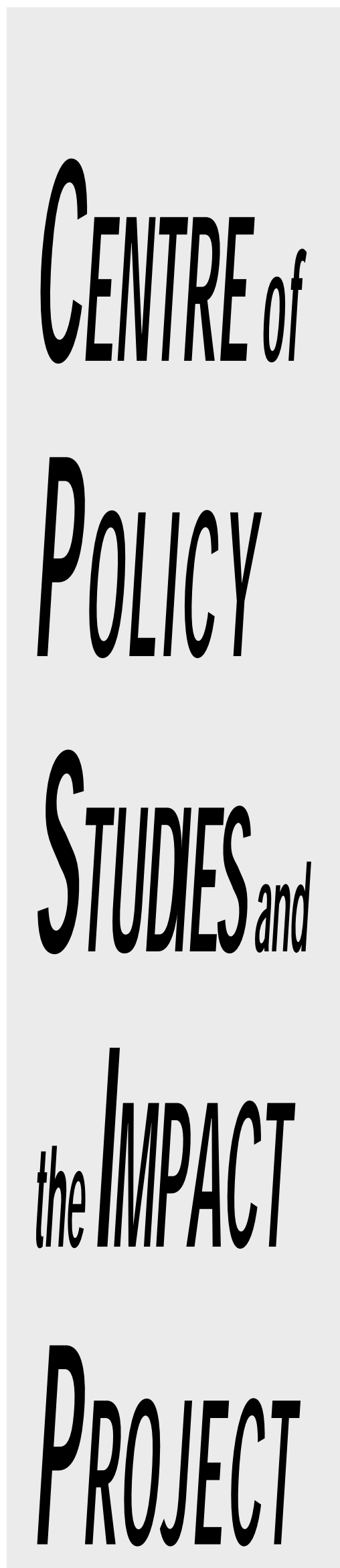

Eleventh Floor

Menzies Building

Monash University Wellington Road

CLAYTON Vic 3168 AUSTRALIA

Telephone:

(03) 905 2398, (03) 9055112

from overseas:

6139052398 or

6139055112

Fax numbers:

(03) 905 2426, (03)905 5486

from overseas:

6139052426 or 6139055486

e-mail

impact@vaxc.cc.monash.edu.au

Keynote address to the

International Congress on Modelling and Simulation

University of Western Australia, 6-10 December 1993

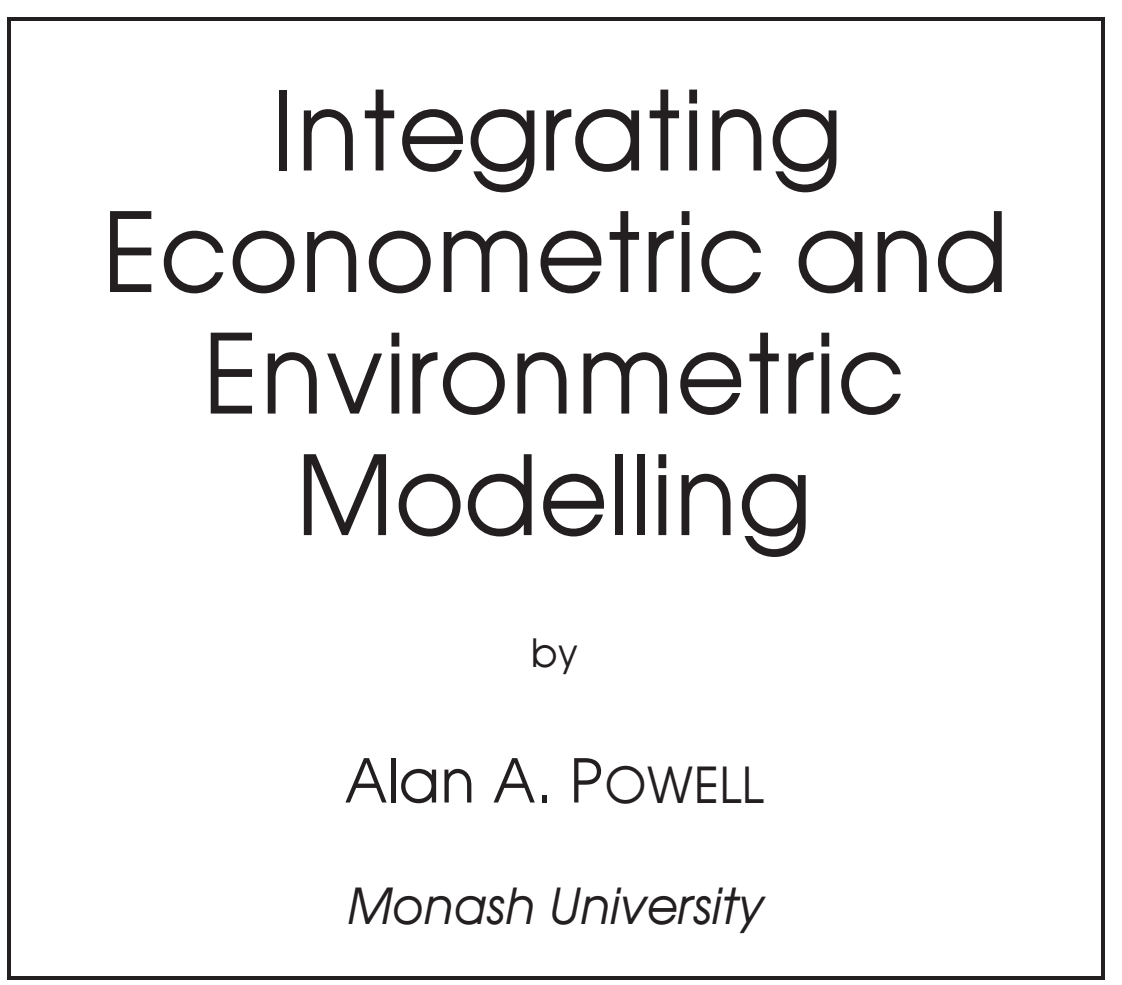

General Paper No. G-102 November 1993

ISSN 10319034

ISBN 0642103135

The Centre of Policy Studies (COPS) is a research centre at Monash University devoted to quantitative analysis of issues relevant to Australian economic policy. The Impact Project is a cooperative venture between the Australian Federal Government and Monash University, La Trobe University, and the Australian National University. During the three years January 1993 to December 1995 COPS and Impact will operate as a single unit at Monash University with the task of constructing a new economy-wide policy model to be known as MONASH. This initiative is supported by the Industry Commission on behalf of the Commonwealth Government, and by several other sponsors. The views expressed herein do not necessarily represent those of any sponsor or government. 


\begin{abstract}
This paper is organized around brief accounts of two modelling initiatives, one with an Australian and the other with a global focus, which have contributed to the policy debate about greenhouse gas abatement. The Australian study involved the combined use of an energy technology programming model, MENSA/MARKAL, with an applied general equilibrium model of the Australian economy, ORANI-F. This interfaced suite of models was used to inform the Australian government's consultations on environmentally sustainable development. The second study involves the Global 2100 model, which also uses a mathematical programming model of energy technology, but couples it to a macro, rather than an applied general equilibrium model. The latter study is one of several, each based on a different model, used as an input to OECD deliberations on greenhouse.

After giving brief accounts of the interfaces between the environmetric and economic component modules of ORANI-F $\backslash$ MENSA/MARKAL and of Global 2100 and a synopsis of what insights into global warming have come out of these models, I set out my ideas about how better interfaces between econometric and environmetric models can be achieved. These suggestions relate more to the 'culture' of modelling than to technicalities. It seems that the technical (often model-specific) problems encountered at the interfaces will be more tractable if everyone involved adopts the same computer modelling language and standards of documentation. Modellers from both sides will have to discipline themselves to keep their component models down to a size that allows the interfaced system to be solved using computer resources that are routinely available.
\end{abstract}




\section{CONTENTS}

ABSTRACT i

1. INTRODUCTION 1

2. WHAT ECONOMETRIC MODELS OFFER 2

3. EXAMPLES OF INTERFACES BETWEEN ENVIRONMETRIC AND ECONOMETRIC MODELS 3

3.1 An Australian model of $\mathrm{CO}_{2}$ abatement 3

3.2 A global model of $\mathrm{CO}_{2}$ abatement 5

4. SYNOPSES OF THE RESULTS OF AN AUSTRALIAN AND A GLOBAL $\mathrm{CO}_{2}$ ABATEMENT STUDY 6

4.1 The Australian study 6

4.2 Manne's global study

5. SCOPE FOR BETTER INTEGRATED MODELS 8

6. CONCLUDING REMARKS 10

REFERENCES

\section{FIGURES}

Figure 1 Flow chart for the interface of ORANI-F with MENSA/ $M A R K A L$.

Figure 2 Flow chart for the interfaces of the energy technology assessment (ETA) modules with the economic modules (MACRO) within regions of Manne's Global 2100 model 


\title{
INTEGRATING ECONOMETRIC AND ENVIRONMETRIC MODELLING
}

\author{
Alan A. Powell \\ Monash University
}

\section{INTRODUCTION}

In this paper 'econometric' will be used in its generic sense, thus embracing all quantitative approaches to economic argument (rather than just those that contain a statistical inferential element). A similarly catholic interpretation will be used for 'environmetric'.

The discussion below is organized around brief accounts of two modelling initiatives, one with an Australian and the other with a global focus, which have contributed to the policy debate about greenhouse gas abatement. Whilst the focus is thus quite specific, the studies are, I think, representative of what is currently afoot in attempts to put together insights from environmental science and from economics.

The paper is organized as follows. Section 2 contains preliminary remarks about what economics has to offer to environmental analysis. As seems well known, economists so far have been better at working out the costs, rather than the benefits, of environmental programs. Attention is drawn to recent progress on the economic measurement of benefits.

Section 3 contains brief accounts of the interfaces between the environmetric and economic component modules of an Australian model used to inform debate during the Australian government's consultations on environmentally sustainable development, and of the Global 2100 model. The latter is one of several models used by the OECD to examine the impact on the world economy of cutting $\mathrm{CO}_{2}$ emissions.

Section 4 contains highlights from the findings of the studies made with the two models. Because some of the insights are difficult to obtain without formal economic logic, they may at first seem surprising to environmental scientists without a background in economics.

Section 5 contains my ideas about how better interfaces between econometric and environmetric models can be achieved. These suggestions relate more to the 'culture' of modelling than to technicalities.

Concluding remarks are offered in Section 6. 


\section{WHAT ECONOMETRIC MODELS OFFER}

Most environmental applications to date of econometric models have concentrated on the costs of achieving given environmental targets. Examples include Jorgenson and Wilcoxen's assessment [11] of the impact of environmental protection legislation upon US economic growth in the 'seventies and 'eighties, the estimation [2] by Adams, Dixon and Parmenter of the probable effects through 2002 on the Australian economy of reducing $\mathrm{CO}_{2}$ emissions so as to meet Australia's commitments to the Toronto targets, and the recent OECD-sponsored comparative study [17] of the global economic impacts of $\mathrm{CO}_{2}$ abatement.

The last-mentioned compares simulations from six multiregional global models: this succeeds in pinpointing many areas where uncertainty about model parameters has major impact on the results. One such key parameter is the likely future rate of autonomous improvement in the efficiency of energy use: "a difference of 0.5 per cent per annum ... can lead to an outcome [i.e., $\mathrm{CO}_{2}$ emissions] in 2100 which is as much as 20 billion tons different (corresponding to over three times the emission level in 1990)" (Dean and Hoeller in [6], p. 13). Other parameters critically affecting the results are those characterizing the degree of substitutability among commodities (especially raw energy forms) in production and consumption.

Economic studies attempting to quantify the benefits of environmental policies have been much rarer than those dealing with costs. I don't think the reason has anything to do with the prejudices of economists as a group. The plain truth is that the benefits are more difficult to characterize economically than the costs. From this it does not follow that they are less significant, nor deemed to be so, by economists! While an appropriate methodology for the measurement of benefits remains a controversial matter (see, for example, the recent volume on the contingent valuation method [9]), some progress does seem imminent - Bergman's environmentally adjusted net national product (ENP) [3] is particularly promising because it is easily related to well understood and accepted modes of economic analysis. Briefly, the method consists of defining an environmental quality index that enters directly into calculations of economic welfare. Although estimation of the parameters of this index inevitably is far from clear cut, Bergman did succeed in calibrating his index (at least in an exploratory way) to Swedish data. The trick was to assume that existing taxes on pollutants gave useable guidance about the public's willingness to pay for environmental quality - presumably, if the taxes had exceeded this willingness, the Swedes would have changed their government at the first opportunity!

The key feature of the studies [2], [3] and [11] cited above, as well as much of the work reported in [17] — and indeed the bulk of quantitative economic work on the environment - is the visualization of the economy as a system. Thus unlike the Club of Rome's first consciousness-raising study of the Limits to Growth [15], most economic modellers have attempted to capture the homeostatic mechanisms at work in the economies they studied. Such mechanisms usually involve increasing relative prices as signals of accelerating 
scarcity, with consequent feedbacks upon the rate at which the scarce entity is utilized, together with the increasing use, where available, of substitutes. This is why empirical estimation of substitution elasticities is so important for the quantitative results produced by economic models.

This use of a systems approach by economists, however, does tend to be restricted to the economy. To do environmental problems justice we need a similar way of viewing the bio-, geo- and atmospheres (or more properly, the global environmental system) and the polity (the national and international political/social systems). And in an ideal world, we would know how to integrate all of them into a single system. But for reasons touched upon below in Section 5, such holism is likely to remain a dream in the foreseeable future.

\section{EXAMPLES OF INTERFACES BETWEEN ENVIRONMETRIC AND ECONOMETRIC MODELS}

Most economists are aware of environmetric modelling at the macro level, but scarcely at all at the micro level. The form in which they expect to receive inputs from environmentally focussed disciplines is as a set of schedules (or better, models) detailing how economic activity (production, investment, consumption) affects the environment. Different technologies will produce different pollutants in different intensities. Under the assumption (made by virtually all economists) that producers seek to minimize costs, any given pollution abatement target will imply a choice of technology.

\subsection{An Australian model of $\mathrm{CO}_{2}$ abatement}

The process of interfacing an energy model with environmental content with a largescale model of a national economy (Australia) is illustrated in Figure 1 . The MENSA/MARKAL model has been described by Adams, Dixon and Jones [1] in the following terms:

'MENSA is a model of Australia's production and use of energy. It was originally developed as a variant of MARKAL which is a general, non-country-specific framework. MARKAL was built under the sponsorship of the International Energy Agency and was first used in Australia in the early 1980s (see Musgrove et al. [16]). In later Australian work, MARKAL was extended by the addition of a regional dimension (Stocks and Musgrove [21]). The resulting ... model is presently maintained by Intelligent Energy Systems in Sydney. The Australian Bureau of Agricultural and Resource Economics (ABARE) also runs [it].'

MENSA/MARKAL is a large dynamic linear programming model which chooses technologies and activities in a detailed representation of the energy sector so as to minimize 'system cost'. ORANI-F (Horridge et al. [10]) is the forecasting version of ORANI (Dixon et al. [7]) which is a large multisectoral model of the Australian economy consisting of many thousands of non-linear equations. ORANI is frequently used for policy analysis (Powell and Snape [19]). 


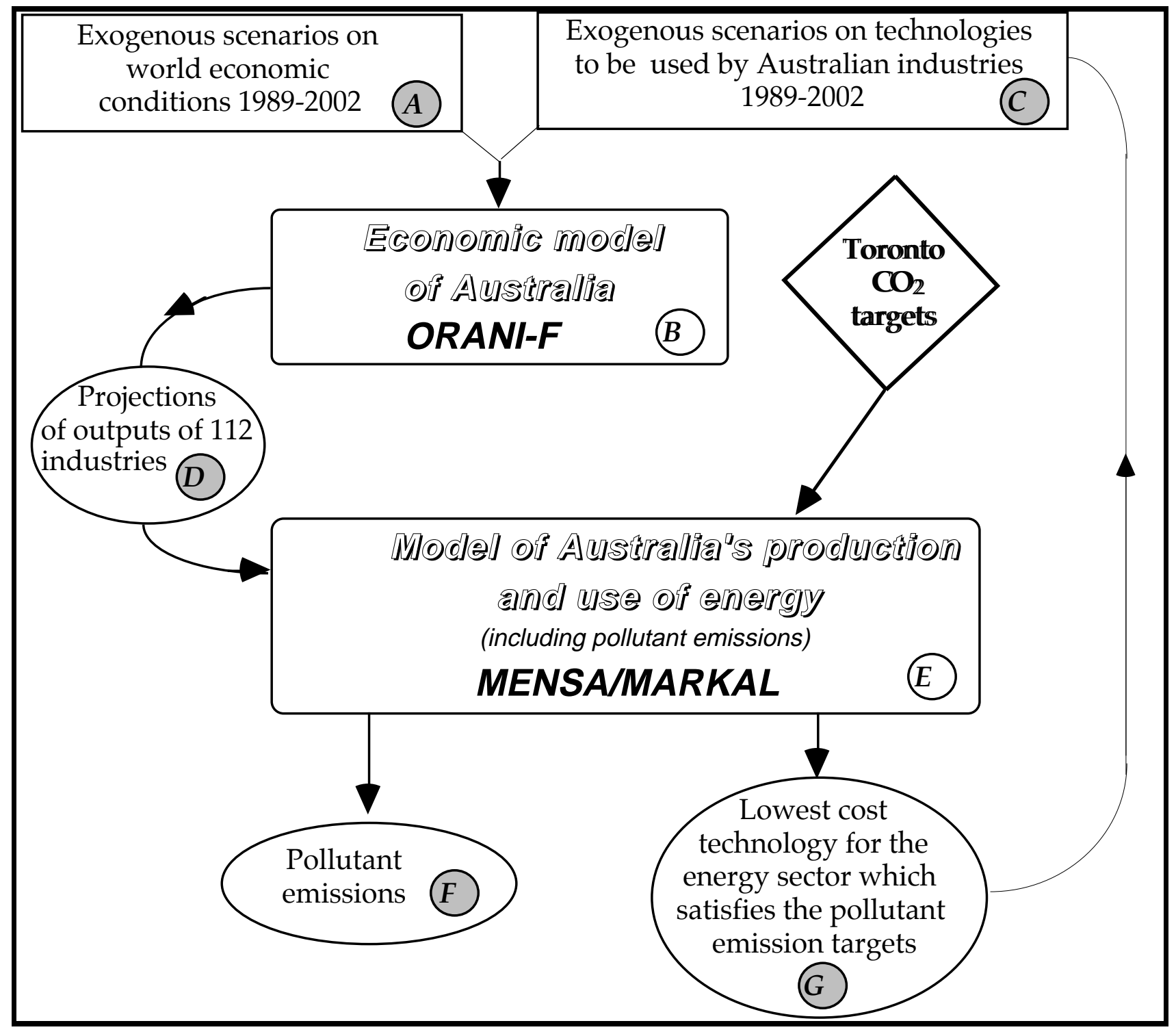

Figure 1 Flow chart for the interface of ORANI-F with MENSA/ MARKAL. The simplest interface has computation terminating at $\boldsymbol{F}$ and $\boldsymbol{G}$ after one pass through; in the most comprehensive (fully simultaneous) interface, computation would cycle back to $C$ and iterate to solution. Note that MENSA/MARKAL solves for the technologies in the energy sector that will minimize overall costs subject to meeting the Toronto emission standards.

Reference [2] reports the results of a study using ORANI-F $\backslash$ MENSA/MARKAL as part of the Australian government's consultations on environmentally sustainable development. The focus of this study was the abatement of $\mathrm{CO}_{2}$ emissions. The exercise commences with the writing of scenarios on the multitude of variables which are exogenous to the Australian economy as modelled by ORANI-F. With very few exceptions, 
Australia is a small enough player on the world scene to allow one to ignore feedbacks from the local economy onto these scenarios. ORANI-F then produces a fairly detailed picture of outputs by industries.

In the next step these output levels are fed to the MENSA/MARKAL model, together with $\mathrm{CO}_{2}$ emission limits based on the Toronto targets. MENSA/MARKAL then searches for the least-overall-cost set of technologies, and activity levels at which to operate them, which deliver $\mathrm{n}$ the outputs previously determined by ORANI-F, whilst staying within the Toronto limits.

At this stage, an inconsistency has arisen. The original technological scenarios on which the ORANI-F industry output projections were based will differ from those identified by MENSA / MARKAL (see panels $G$ and $C$ of Figure 1). ORANI-F can be resolved under the new technological scenarios, yielding a new set of industry projections; and so on, until a full simultaneous solution of the interfaced system is found.

\subsection{A global model of $\mathrm{CO}_{2}$ abatement}

Manne's study [13] uses a similar set-up within each of five linked regional models one each for the USA, the other OECD (OOECD) countries, the former USSR, China and the rest of the world (ROW). The model (built by Manne and Richels [12]) is geopolitically comprehensive - a must for global analysis of environmental issues. Its environmetric components are generically known as ETA, Energy Technology Assessment models, while its econometric models go under the generic label of MACRO. Figure 2 depicts one of the five ETA $\backslash$ MACRO interfaces.

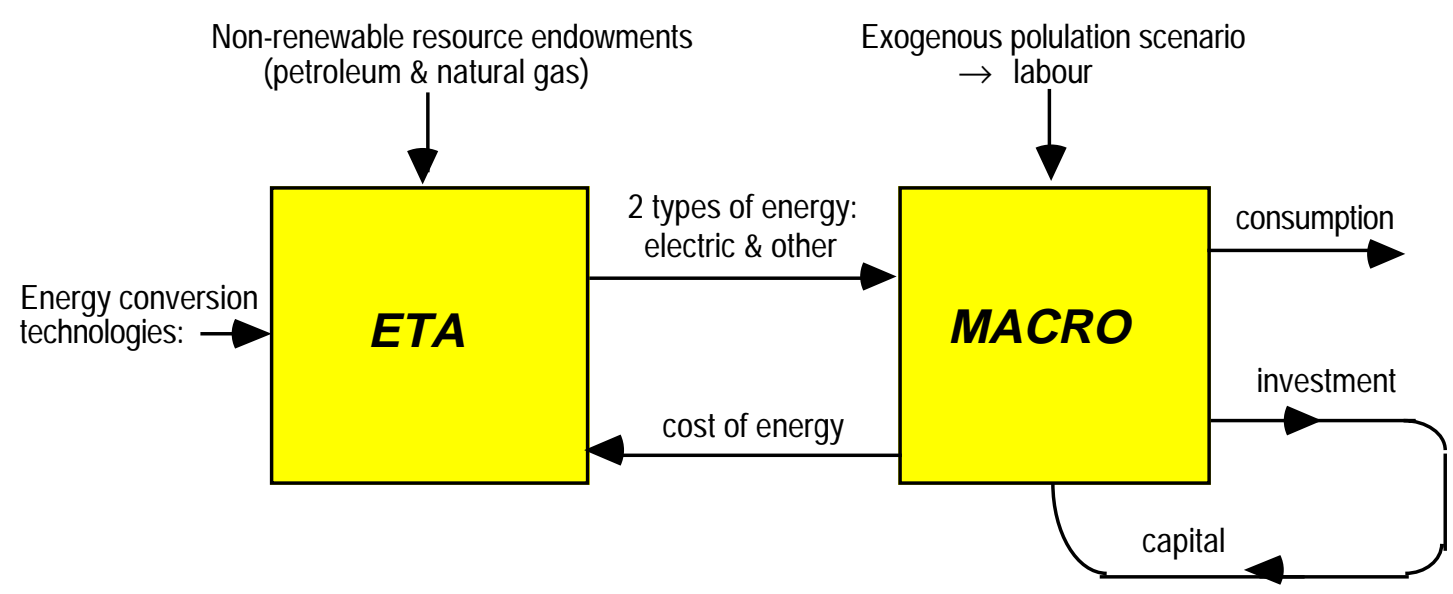

Figure 2 Flow chart for the interfaces of the energy technology assessment (ETA) modules with the economic modules (MACRO) within regions of Manne's Global 2100 model (after Manne [13]).

The MACRO models are much less detailed than ORANI-F. Thus relative to the Australian study, Manne's global study may miss changes in the energy (and pollutant) 
intensity of GDP that are brought about by compositional changes in the economy (say favouring energy-efficient industries under the imposition of a carbon tax). This, of course, could be fixed ex post by changing the values of certain macro coefficients within Global 2100 (the name of the complete model obtained by linking the five ETA \MACRO regional models) to reflect the changed composition of GDP. But for guidance on this issue, separate recourse to more detailed national models would be necessary. Nevertheless, the (relatively) compact size of Global 2100 does have advantages, as will be seen below.

In practice, in the Australian study [2], the iterative procedure depicted in Figure 1 was terminated after one recycling from $G$ to $C$. The reasons for this curtailment tell us something about the practicality of building interfaces between large models, especially ones with disparate parentage. On the other hand, in Manne's study [13], the full simultaneous interface was implemented. Before further discussing the interfacing issue, a brief survey of the simulation results from the two studies is given in Section 4 .

\section{SYNOPSES OF THE RESULTS OF AN AUSTRALIAN AND A GLOBAL $\mathrm{CO}_{2}$ ABATEMENT STUDY}

\subsection{The Australian study}

Not surprisingly, the impact of $\mathrm{CO}_{2}$ abatement policies is felt most directly in the energy sector. Achievement of the targets, according to MENSA/MARKAL, results in significant increases in the costs of electricity generation as natural gas is substituted for coal. According to ORANI-F, this results in reduced real GDP and wages. Because existing coal-burning equipment must be scrapped early, and because the cleaner replacement technologies are more expensive, additional capital needed in the electricity generating sector leads to increased levels of investment which crowd out consumption.

The implications for the coal industry depend on what is happening in the rest of the world. If world demand for coal stays strong (which suggests that globally the Toronto targets are not being met), then the coal that would have been used by Australian industries (especially by producers of electricity) is simply exported - along with its pollution potential. If reduced overseas demand prevents such exportation, then the local coal mining industry contracts substantially.

The issues canvassed in the preceding paragraph raise the prospect which has seriously worried policy makers in the OECD countries: would a rigorous unilateral enforcement of the Toronto targets by its member countries just lead to the relocation of polluting industries in the Third World? Is it possible, likely even, that global emissions of greenhouse gases would not decline? Some of the global studies reported in [17] shed light on these questions. 


\subsection{Manne's global study}

Growth of population and of the economies of less developed regions features prominently in the simulations reported in the OECD comparative models study [17]; Manne's study is no exception. The common exogenous population scenario used by all six models entailed a rise in population

'from 5.3 billion in 1990 to 9.5 billion in 2050 and to 10.4 billion by 2100, by which time it is hardly growing at all (World Bank projections); nearly all of the growth is in China and other developing countries ... ' (Dean and Hoeller, [6], p.14).

In the common base-line (business-as-usual) scenario, the rate of growth of real GDP was projected to slow down to 1 per cent per annum by the year 2100 in the OECD, and to fall from 4 to 3 per cent per annum for developing countries. In this scenario, oil prices are projected to rise in real terms by six 1990 US dollars per barrel per decade, reaching 50 (1990) US dollars in 2030, and remaining unchanged after that date. The three $\mathrm{CO}_{2}$ abatement scenarios have emissions growing in all regions by 1, 2 and 3 percentage points per annum less than in the business-as-usual scenario. These abatement scenarios were chosen to standardize the simulations across the six models in the OECD study; they have no policy significance.

The 2 per cent abatement scenario 'would require absolute cuts [in $\mathrm{CO}_{2}$ emissions, relative to 1990] in the OECD and in the former Soviet Union and allow some continued, albeit very low growth elsewhere' (Dean and Hoeller [6], p.14). In Manne's Global 2100 simulations, the 2 per cent scenario produces a fall in total carbon emissions from about 6 billion tons in 1990 to about $4_{2}^{\frac{1}{2}}$ billion tons in 2100 ([13], p. 58).

The issue of relocation of polluting activities is addressed head-on in Global 2100.

'...it is assumed that carbon emissions are imposed in such a way as to have minimum impact on economic growth. For a market economy, this could be accomplished by auctioning off carbon emission rights.' (Manne [13], p. 59).

Making such rights internationally tradeable allows the abatement targets to be reached at considerably lower cost than could be achieved otherwise. The former USSR has vast reserves of natural gas which it would not be able to exploit under the 2 per cent scenario (since to do so would involve exceeding its allowable emissions). Natural gas is a cheaper energy form than the 'back-stop' technologies that have to be adopted in the OECD countries by the middle of the next century. World demand for energy-intensive products can be satisfied at a lower cost if the OECD is allowed to sell some of its emission quotas to the former USSR. If international trade in emission rights is allowed, the former USSR becomes a substantial purchaser of emission rights, importing the right to emit 0.3 billion tons annually of carbon from each of the US and the OOECD in 2100.

The significance for China and other developing countries of the Global 2100 simulations is made explicit by Manne in the following quotation: 
'As of 1990, the industrialized countries (USA, OOECD and [former] USSR) generated about 2/3 of the global emissions total. According to Global 2100, their emissions continue to grow during the 21st century, but those from China and the ROW will increase at a much more rapid rate. The overall result is that the share of the USA, OOECD and USSR drops to only 30 per cent by the year 2100. Clearly, if there is to be a meaningful global agreement, the currently industrialized countries cannot be the only participants. China and the ROW will also have to bear a portion of the burden.' ([13], p. 57)

What sorts of sacrifices are involved in reducing $\mathrm{CO}_{2}$ emissions? Under the 2 per cent abatement scenario, Global 2100 puts the costs in 2100, as a percentage deviation below base-line GDP, at the following values:

\begin{tabular}{|ll|ll|ll|ll|ll|}
\hline US & 3.1 & OOECD & 1.9 & $\begin{array}{llll}\text { former } \\
\text { USSR }\end{array}$ & 5.6 & CHINA & 5.0 & ROW & 5.6 \\
\hline
\end{tabular}

Source: Manne [13], p.61

All of the results quoted above, of course, come with caveats. And there are substantial differences between the Global 2100 results and those obtained with other models. But all things considered, a good measure of agreement seems to be emerging, at least between Manne's work and that encapsulated in the OECD's GREEN model (see Oliveira Martins et al. [17] and Manne [14]).

\section{SCOPE FOR BETTER INTEGRATED MODELS}

What scope exists for better integration of environmetric and econometric models? And what pay-offs can be expected from better integration?

In the case of the two models discussed above, a serious attempt at integration was made. It was not completely successful, however, in the case of the Australian model. This was in part due to tight deadlines for the completion of the study but also due to more fundamental factors. Both MENSA/MARKAL and ORANI-F are large models, and at least in the case of (the successor to) ORANI-F, still growing. In stand-alone mode their solution requires access to superior hard- and software. Mounting both models on the same computer platform under a single controlling program would put the enterprise at the frontier of computing technology. We will not be seeing such large models integrated as a routine matter, at least for some time to come.

Compared to ORANI-F, Global 2100 has a regional dimension to cope with, as well as detailed temporal disaggregation. (The successor to ORANI-F, the MONASH model currently under construction, will have detailed temporal disaggregation.) On the other hand, the dimensionality of the economic models in Global 2100 is tiny by comparison with ORANI-F. This simplification allows the former model to be solved with a fully simultaneous interface (admittedly, with access to superlative computation resources human and otherwise). 
Questions of size aside, the existence of strong discipline-based imperatives also limits scope for integration. As the availability of hard- and software improves, there is always a backlog of enhancements that the modellers in each camp are just itching to implement. As the horizon of possibilities expands, what we tend to get is bigger and better environmetric and bigger and better econometric models, rather than a better integration of the two.

Communication between disciplines is rarely easy. Chances are that the econometric and environmetric models to be interfaced will involve modellers from different disciplines. If they are to communicate, a sine qua non is comprehensive documentation of the models - not only their mathematics and their computer systems, but also plain language descriptions of their principal mechanisms. To this must be added complete documentation of data and parameter files, with their provenance noted.

As formidable as the obstacles mentioned above may be, environmental scientists and economists will make the effort where the pay-offs seem substantial to both. Given that the environment now is permanently on the political agenda, many instances are sure to arise in which the incentives to co-operate are strong. If global warming proceeds in the manner predicted by many climatologists, the pressure to develop integrated models will become irresistible. Given the useful insights coming out of models with relatively primitive interfaces, however, one should not become obsessed with the idea of integration for its own sake. On occasions it will suffice to 'man-handle' the interchange of information between the models.

How can better interfaces be built? Because the larger models are already at the limits of routine computation, prototypes of interfaced models must be developed in exactly the same way that prototypes are developed for any large model: all non-essential dimensionality must be shed. In the case of models in the ORANI family the number $\mathrm{N}$ of industries is routinely aggregated from over 100 to about a dozen during the exploration of new developments; with solution times approximately proportional to $\mathrm{N}^{3}$, this reduction in size makes it possible to turn around developmental runs many times during the course of a day. Similar condensations of environmetric prototypes must be feasible.

After prototype development, the size of operational version of the interfaced model will necessarily increase. Given the difficulties experienced with manipulating and solving very large models, this process of allowing the model to 'fill out' should be circumspect. An extension of Occam's razor will be helpful here. We should be asking ourselves: is the additional complexity really necessary to achieve the purposes of the model? Or would a simpler structure supplemented by sensitivity analysis achieve the same ends?

With dimensionality reduced to manageable proportions, the question remains as to how to implement the interface. There should be no problem in identifying a natural division of 'labour': each of the component models should be used to endogenize the variables with respect to which that model is stronger. In the examples above, the strength of the environmetric models was in technological choice, and in quantifying the pollutant 
emissions flowing from the use of each technology. The strength of the economic models was in assessing how changing cost conditions led to changed production, consumption, international trading patterns, and living standards.

Finally, as has been stressed above, computation is a non-trivial issue. Clearly, the choice of hard- and software would best be made jointly. There exist powerful modelling languages ([4], [5], [8]) commonly used by economic modellers which almost certainly are also suitable vehicles for the implementation of environmetric models. Quite likely there are computer packages familiar to environmental scientists (but not to me) which economic modellers would find useful. Ideally the econometric and the environmetric modules of the combined model would be written in the same computer modelling language and have access to the same battery of solvers (solution algorithms). If the modelling language used is transparent (i.e., close to ordinary algebra), then provided ample comments are retained, the computer implementable version of the model provides definitive documentation and allows easy transfer between professionals and computer installations - at least this has been the experience of the community of economic modellers using the GEMPACK [5], [8] and GAMS [4] modelling languages.

\section{CONCLUDING REMARKS}

The perception of a global environmental crisis (greenhouse) arose just as economic modellers had mastered the art of simulating the impacts of diverse shocks on fairly detailed computer representations of economies (the technique is known as computable or applied general equilibrium analysis). The subsequent large research investment by national and international organizations into abatement of greenhouse gases (especially $\mathrm{CO}_{2}$ ) created the necessity of interfacing models built by scientists, engineers and operations researchers with models built by economists. Results to date are promising. However it seems that the technical (often model-specific) problems encountered at the interfaces will be more tractable if everyone involved adopts the same computer modelling language and standards of documentation. Modellers from both sides will have to discipline themselves to keep their component models down to a size that allows the interfaced system to be solved using computer resources that are routinely available.

\section{Acknowledgments}

I am grateful to Philip D. Adams for help with the description of MENSA/MARKAL and for comments, to Kenneth R. Pearson for comments, and to Joaquim Oliveira Martins for his timely supply of OECD documentation. Errors are exclusively mine. 


\section{REFERENCES}

[1] Adams, Philip D., Peter B. Dixon and Barry Jones, The MENSA model: an exposition. Centre of Policy Studies, Monash University, Discussion Paper D155, July 1992.

[2] Adams, Philip D., Peter B. Dixon and Brian R. Parmenter, Prospects for the Australian economy 1989-90 to 2001-02: ORANI-F projections for the ecologically sustainable development working groups. Chapter 6 in Hargreaves, C. (ed.), Macroeconomic modelling of the long run pp. 119-157. Edward Elgar, Aldershot (U.K.), 1992.

[3] Bergman, Lars, General equilibrium costs and benefits of environmental policies: some preliminary results based on Swedish data. Paper presented at the Fondazione ENI Enrico Mattei conference, 'Modelling Environment Economy Linkages', Milan, December 1992; and at the Fourth CGE Modeling Conference, University of Waterloo, Ontario, October 1993.

[4] Brooke, Anthony, David Kendrick and Alexander Meeraus, GAMS: a user's guide, Scientific Press, Redwood City, 1988.

[5] Codsi, G. and K. R. Pearson GempacK: General-purpose software for applied general equilibrium and other economic modellers, Computer Science in Economics and Management. 1 189-207, 1988.

[6] Dean, Andrew and Peter Hoeller, Costs of reducing $\mathrm{CO}_{2}$ emissions: evidence from six global models. In OECD [17], pp. 13-36.

[7] Dixon, P. B., B .R. Parmenter, J. Sutton and D. P. Vincent (1982) ORANI: a multisectoral model of the Australian economy. North-Holland, Amsterdam, 1982.

[8] Harrison, W. Jill and K.R. Pearson An introduction to GEMPACK, Monash University, Clayton, Vic., Australia, Impact Project, GEMPACK document GPD-1, First edn, April 1993.

[9] Hausman, J. A. (ed.), Contingent valuation - a critical assessment. North-Holland, Amsterdam, 1993.

[10] Horridge, J. M., B. R. Parmenter and K. R. Pearson, ORANI-F: a general equilibrium model of the Australian Economy. Economic and Financial Computing 3(2) 71-140, 1993.

[11] Jorgenson, Dale W. and Peter J. Wilcoxen, Environmental regulation and U.S. economic growth. Rand Journal of Economics 21(2) 314-340, 1990.

[12] Manne, A. S. and R. Richels, Buying greenhouse insurance - the economic costs of $\mathrm{CO}_{2}$ emission limits. MIT Press, Cambridge, Massachusetts, 1992. 
[13] Manne, Alan S., Global 2100: alternative scenarios for reducing carbon emissions. In OECD [17], pp. 55-65.

[14] Manne, Alan S., International trade - the impact of unilateral carbon emission limits. Paper presented at the International Conference on the Economics of Climate, OECD/IEA, Paris, June 1993; and at the Fourth CGE Modeling Conference, University of Waterloo, Ontario, October 1993.

[15] Meadows, Donella H. et al. The limits to growth: a report to the Club of Rome's project on the predicament of mankind. Earth Island Ltd, London, 1972.

[16] Musgrove, A. R. deL., K. J. Stocks, P. Essam, D. Le, J. V. Hoetzl, Exploring some Australian energy alternatives using MARKAL. CSIRO, Division of Energy Technology, Lucas Heights Research Laboratories, NSW, Technical Report TR2, 1983.

[17] OECD, The costs of cutting carbon emissions: results from global models. OECD Documents, Paris, 1993.

[18] Oliveira Martins, Joaquim, Jean-Marc Burniaux, John P. Martin and Giuseppe Nicoletti, The costs of reducing $\mathrm{CO}_{2}$ emissions: a comparison of carbon tax curves with GREEN. In OECD [17], pp. 67-94.

[19] Powell, Alan A. and Richard H. Snape, The contribution of applied general equilibrium analysis to policy reform in Australia. Journal of Policy Modeling 15(4) 393-414, 1993.

[20] Rutherford, T.F., General equilibrium modelling with MPS/GE. Department of Economics, University of Western Ontario, London, Ontario, 1989.

[21] Stocks, K. J. and A. R. deL. Musgrove, MENSA - a regionalized version of MARKAL, the IEA linear programming model for energy systems analysis. Energy Systems and Policy 8(4) 313-348, 1984. 